\title{
Risk factors appraisal for Hypertension among rural community of Western Maharashtra: A field-based study
}

\author{
Sachin B Jadhav ${ }^{1}$, Asmita S Jadhav²*, Kalpak S Kadarkar ${ }^{3}$, Priya M Prabhu ${ }^{4}$ \\ $\left\{1,4\right.$ Associate Professor, ${ }^{3}$ Assistant Professor, Department of Community Medicine $\}$ \{ ${ }^{2}$ Associate Professor, Department of Anatomy \\ Government Medical College, Miraj, Maharashtra, INDIA. \\ Email: dr latesh@rediffmail.com
}

Abstract Background: Hypertension is a leading risk factor for cardiovascular diseases. WHO has drawn attention to the fact that, Hypertension and related cardiovascular diseases are our modern epidemic. This contributes to high morbidity, cardiovascular disabilities and increasing mortality in the population. Such trends put an excessive burden on the quantum and quality of health care and necessitate more focus on more costly secondary and tertiary health care. Methods: A field based cross sectional descriptive study was conducted among rural population above 40 years. A pretested and structured questionnaire was used to record requisite information. A JNC VII criterion was used for blood pressure measurements. Data was analyzed with univariate and multivariate analysis. Results: Overall prevalence of hypertension among study participants observed was 5.92\% (213 cases). Study participants having 'Sedentary' type of physical activity showed maximum number of cases (117 cases) than 'Moderate' or 'Heavy' physical activity group. Prevalence of hypertension was seen higher among upper class social-economic status population. Study participants consuming alcohol with varied frequency showed 158 cases out of total 213 cases while non-alcoholic participants (1995), had 55 cases of hypertension. Conclusions: The risk of hypertension increases with Advancing age positive family history and in male gender. Use of tobacco, alcohol consumption and resorting to non-vegetarian diet are the other contributory factors and the risk is more in the widowed persons as well as in those who are obese. Screening programmes with continuing health education for timely diagnosis and further treatment are to be stressed at policy formation.

Keywords: Hypertension, Risk factors, Physical activity.

*Address for Correspondence:

Dr Asmita S Jadhav, Associate Professor, Department of Anatomy, Government Medical College, Miraj, Maharashtra, INDIA.

Email: $\underline{\text { dr latesh@,rediffmail.com }}$

Received Date: 06/03/2021 Revised Date: 12/04/2021 Accepted Date: 17/05/2021

DOI: https://doi.org/10.26611/10111823

This work is licensed under a Creative Commons Attribution-NonCommercial 4.0 International License. $(\boldsymbol{C c})$ EY-NC

\begin{tabular}{|l|l|}
\hline \multicolumn{2}{|c|}{ Access this article online } \\
\hline Quick Response Code: & Website: \\
\hline & www.medpulse.in \\
\hline & \\
& \\
\hline
\end{tabular}

\section{INTRODUCTION}

During the recent years, the incidence of cardiovascular diseases (CVDs) has shown an increasing trend in India. The risk of developing CVDs in Indian population is much higher than that in other countries. Hypertension which in turn risk factor for CVD is the major cause of disability affecting the quality of life of millions of people each year. CVD deaths are concentrated in people of working age between 35-64 years, (in whom 35\% of CVD deaths occur). The risk operates in a continuum, with modest elevation of many risk factors having a multiplicative effect. Identifying and modifying these risk factors have been recommended as a strategy for prevention and control of Hypertension in various settings. ${ }^{1}$ Hypertension epidemic is driven by demographic and socioeconomic changes that influence the living, eating, and working habits of population. Such changes have resulted in population-wide escalation in maj or CVD risk factors like smoking, obesity, cholesterol concentrations, and dysglycemia and these risk factors have increased steeply 
in many developing countries in the last two decades. ${ }^{2}$ Hypertension is a leading risk factor for cardiovascular diseases. WHO has drawn attention to the fact that, Hypertension and related cardiovascular diseases are our modern epidemic i.e. the disease that affects younger population, and not an unavoidable attribute of ageing. It is estimated that if the incidence of such diseases is brought to zero, it would increase the life expectancy by 3 to $9 \%$. It is associated with high social cost. ${ }^{3}$ In India, the problem is ever increasing. It is observed that, these problems are occurring with more frequency and severity and at the same time, the problems are observed at an earlier age. To add to this, females are also being increasingly affected. This contributes to high morbidity, cardiovascular disabilities and increasing mortality in the population. Such trends put an excessive burden on the quantum and quality of health care and necessitate more focus on more costly secondary and tertiary health care. ${ }^{4}$ Elevated blood pressure have root in the changing life styles and behavioral patterns. Such diseases are amenable for prevention by simpler, non-costly, affordable and practicable non- pharmacological interventions.

Objectives: To study the prevalence of hypertension in the community with related demographic and socio-economic factors. To study and analyze observed risk factors of hypertension. To suggest the possible recommendations for prevention and control.

\section{METHODOLOGY}

A Cross sectional descriptive field-based study carried out at Tasgaon rural town, a field practice area of Government Medical College, Miraj which is located in Sangli district of Maharashtra and it caters to the major health needs of the local and nearby areas. It has total population of 39,300 according to the latest house to house survey.

The study population comprised of the individuals above 40 years of age. Study subjects were proportionately selected by Stratified random sampling from four sectors. These four sectors have been already defined and demarcated by Rural Health Training Centre, Tasgaon for the purpose of health care delivery. The sample size was calculated by taking anticipated prevalence of 5\% from various previous studies and permissible error $15 \%$ of anticipated prevalence, sample size calculated as 3200 . Considering $10 \%$ approximate nonresponse rate, Total final sample size derived was rounded of to 3600 . Ethical approval was obtained before start of the study.

Data collection and Analysis: A pretested and semi structured proforma was constructed and validated containing various information about desired parameters. Considering Inclusion and Exclusion (Not willing, having critical illnesses, less than 40 yrs. of age) criteria, all eligible study participants were informed the nature of study and administered an informed consent. House to house survey was carried with the help of rural health training centre staff. Data was collected during the period of One year. (January 2007 to December 2007). Patients detected to be having active and acute complaints related to cardiovascular disorders were referred to the Government Medical College, Miraj for pertinent investigations and further management.

Standardized ISI marked mercury sphygmomanometer, Standardized Flexible metal Measuring tape and Standardized Weighing machine were the instruments used after requisite standardization and calibration to minimize the instrumental error. Using these instruments, Height, Weight and Blood pressure measurements were made as per the standard techniques. As per JNC criteria ${ }^{5}$, Hypertension was defined. Systolic blood pressure $\geq 140$ $\mathrm{mmHg}$ or Diastolic blood pressure $\geq 90 \mathrm{mmHg}$ or the person is on antihypertensive medications. Collected data was checked and processed. Descriptive and inferential data analysis was carried out by using suitable tests of significance. Interpretation of data established through linking results of the present study with those of others along with some explanatory thoughts. Association between selected variables was tested for significance by using univariate as well as Multivariate Analysis techniques.

\section{RESULTS}

Out of total 3600 study participants, 2324 were males while 1276 were females. Minimum age recorded was 40 years (male) and maximum was 88 years (male). Mean age was 56 years $( \pm 13.5)$ Age wise increase in the prevalence of hypertension was seen among study participants. Age group more than 60 years showed maximum cases of hypertension (61 cases). (Table I) Overall prevalence of hypertension among study participants observed was $5.92 \%$ (213 cases). In Males, it was 7.27\% (169 cases) while in females, it was $3.44 \%$ (44 cases). Mean systolic blood pressure was $128( \pm 13 \mathrm{mmHg})$ while diastolic blood pressure $81.3 \mathrm{mmHg}( \pm 6.3 \mathrm{mmHg})$ (Table II) Majority of the subject were belonging to Hindu religion (80.3\%) while rest were Muslims and others. $91.8 \%$ of the study population was currently married whereas $8.9 \%$ of the population was illiterate. Mental stress was observed in $83 \%$ of the participants with the help of mental stress score scale. ${ }^{6}$ Occupation wise, around $20 \%$ population was not involved in any job, while about $12 \%$ involved in some managerial works. 'No job' Occupation group showed around one third of total cases ( 88 cases) of hypertension. $37 \%$ of the total study participants were having sedentary work. Study participants having 'Sedentary' type of physical activity showed maximum number of cases (117 cases) than 'Moderate' or 'Heavy' physical activity group. 
With regard to socio-economic status, about one fourth population was belonging to lower socio-economic status according to Modified BG Prasad classification ${ }^{5}$. Prevalence of hypertension was seen higher among upper class social-economic status population $(10.9 \%)$ About 501 study participants had family history of hypertension. Around $2.3 \%$ participants were having body mass index more than 25 . A total of $33 \%$ participants were belonging to mixed dietary pattern habit. Out of those, $67 \%$ of subjects having mixed dietary pattern were showing $75 \%$ of total cases (161 cases)where as 33\% of subjects having vegetarian dietary pattern showed $25 \%$ of cases ( 52 cases). $44.5 \%$ of the study participants (all males) were consuming alcohol with varied frequency and $51.3 \%$ were consuming some form of tobacco use. Study participants consuming alcohol with varied frequency showed 158 cases out of total 213 cases while non-alcoholic participants (1995), had 55 cases of hypertension. Similarly, habit of tobacco use in any form, smoking or smokeless, was seen in 51.3\% of total participants (both gender). It was observed that 83 $\%$ of total hypertension cases where having habit of tobacco use.

Table I: Socio Demographic characteristics of Study Participants

\begin{tabular}{|c|c|c|c|c|c|c|}
\hline \multirow[t]{2}{*}{ Characteristics (Variable) } & \multicolumn{2}{|c|}{ Male } & \multicolumn{2}{|c|}{ Female } & \multicolumn{2}{|c|}{ Total } \\
\hline & No. & Cases & No. & Cases & No. & Cases \\
\hline \multicolumn{7}{|c|}{ Age group (in years) } \\
\hline $41 \geq 50$ & 633 & 43 & 412 & 10 & 1045 & 53 \\
\hline $51 \geq 60$ & 739 & 32 & 386 & 9 & 1125 & 41 \\
\hline $61 \geq 70$ & 653 & 45 & 338 & 13 & 991 & 58 \\
\hline $71 \geq 80$ & 263 & 32 & 127 & 9 & 390 & 41 \\
\hline$>80$ & 36 & 17 & 13 & 3 & 49 & 20 \\
\hline \multicolumn{7}{|c|}{ Religion } \\
\hline Hindu & 1833 & 125 & 1056 & 38 & 2889 & 163 \\
\hline Muslim & 445 & 42 & 210 & 06 & 655 & 48 \\
\hline Others & 46 & 02 & 10 & 00 & 56 & 02 \\
\hline \multicolumn{7}{|c|}{ Marital status } \\
\hline Married & 2227 & 142 & 1078 & 16 & 3305 & 158 \\
\hline Separated & 04 & 01 & 05 & 00 & 09 & 01 \\
\hline Widow/er & 93 & 26 & 193 & 28 & 286 & 54 \\
\hline \multicolumn{7}{|c|}{ Educational status } \\
\hline Illiterate & 697 & 77 & 547 & 34 & 1244 & 111 \\
\hline Primary & 451 & 28 & 504 & 5 & 955 & 33 \\
\hline Secondary & 1124 & 56 & 225 & 5 & 1349 & 61 \\
\hline Graduation and above & 52 & 8 & 0 & 0 & 52 & 8 \\
\hline \multicolumn{7}{|c|}{ Occupation } \\
\hline No Job & 517 & 72 & 245 & 16 & 762 & 88 \\
\hline Unskilled & 214 & 7 & 120 & 4 & 334 & 11 \\
\hline Skilled & 1530 & 83 & 910 & 24 & 2440 & 107 \\
\hline Managerial & 63 & 7 & 1 & 0 & 64 & 7 \\
\hline \multicolumn{7}{|c|}{ Socio-Economic status } \\
\hline Upper & 44 & 04 & 11 & 02 & 55 & 06 \\
\hline Upper Middle & 538 & 27 & 109 & 04 & 647 & 31 \\
\hline Middle & 677 & 63 & 315 & 04 & 992 & 67 \\
\hline Lowe Middle & 856 & 54 & 623 & 23 & 1479 & 77 \\
\hline Lower & 209 & 21 & 218 & 11 & 427 & 32 \\
\hline \multicolumn{7}{|c|}{ Family history of HTN } \\
\hline Negative & 1960 & 90 & 1139 & 24 & 3099 & 114 \\
\hline Positive & 364 & 79 & 137 & 20 & 501 & 99 \\
\hline \multicolumn{7}{|c|}{ Physical activity } \\
\hline Sedentary & 868 & 93 & 459 & 24 & 1327 & 117 \\
\hline Moderate & 1258 & 67 & 713 & 19 & 1971 & 86 \\
\hline Heavy/strenuous & 198 & 09 & 104 & 01 & 302 & 10 \\
\hline \multicolumn{7}{|c|}{ Dietary Pattern } \\
\hline Vegetarian & 717 & 33 & 476 & 19 & 1193 & 52 \\
\hline Mixed diet & 1607 & 136 & 800 & 25 & 2407 & 161 \\
\hline \multicolumn{7}{|c|}{ Alcohol } \\
\hline Non consumption & 719 & 11 & 1276 & 44 & 1995 & 55 \\
\hline
\end{tabular}




\begin{tabular}{|c|c|c|c|c|c|c|}
\hline Alcohol consuming & 1605 & 158 & 00 & 00 & 1605 & 158 \\
\hline \multicolumn{7}{|c|}{ Tobacco use } \\
\hline Yes & 1294 & 141 & 555 & 36 & 1849 & 177 \\
\hline No & 1030 & 28 & 721 & 08 & 1751 & 36 \\
\hline \multicolumn{7}{|c|}{ BMI } \\
\hline$<25$ & 1731 & 86 & 1004 & 28 & 2735 & 114 \\
\hline$>25$ & 593 & 83 & 272 & 16 & 865 & 99 \\
\hline \multicolumn{7}{|c|}{ Mental stress score } \\
\hline No stress $(0-40)$ & 403 & 25 & 181 & 04 & 584 & 29 \\
\hline Less stress (41-200) & 1606 & 94 & 915 & 30 & 2521 & 124 \\
\hline More stress $(201+)$ & 315 & 50 & 180 & 10 & 495 & 60 \\
\hline
\end{tabular}

Table II: Prevalence of Hypertension

\begin{tabular}{ccccccc}
\hline Characteristics & \multicolumn{2}{c}{ Male } & \multicolumn{2}{c}{ Female } & \multicolumn{2}{c}{ Total } \\
\cline { 2 - 6 } & No. & Cases & No. & Cases & No. & Cases \\
\hline Total & 2324 & 169 & 1276 & 44 & 3600 & 213 \\
& & $(7.27 \%)$ & & $(3.44 \%)$ & & $(5.92 \%)$ \\
\hline
\end{tabular}

In the present study, all in all 14 variables were analyzed in relation to occurrence of hypertension. These were subjected to univariate analysis using $\chi 2$ test to study the level of statistical association either in total study group as well as in the male / female gender separately. These variables are summarized in the Table III.

\begin{tabular}{|c|c|c|}
\hline Sr.No. & Variable & $\chi 2$ value, degree of freedom, $p$ value, inference \\
\hline 1 & Age & $\begin{array}{l}\text { Total } \chi 2=57.43, d f=1, p<0.001, \text { significant. } \\
\text { Male } \chi 2=43.12, d f=1, p<0.001, \text { significant. } \\
\text { Female } \chi 2=12.67, d f=1, p<0.001, \text { significant. }\end{array}$ \\
\hline 2 & Gender & Total $\chi 2=21.6, d f=1, P<0.01$ Significant. \\
\hline 3 & Marital status & $\begin{array}{l}\text { Total }-\chi 2=72.8, d f=1, P<0.001 \text { high sig. } \\
\text { For Males }-\chi 2=60.3, d f=1, p<0.001 \text {, high sig. } \\
\text { For Females- } \chi 2=76.7, d f=1, p<0.001 \text {, high sig. }\end{array}$ \\
\hline 4 & Literacy status & $\begin{array}{l}\text { Total }-\chi 2=38.4, d f=4, P<0.001 ; \text { high sig. } \\
\text { For males }-\chi 2=29.3, d f=4, p<0.001 ; \text { high sig. } \\
\text { For females }-\chi 2=22.7, d f=2, p<0.001 ; \text { high sig. }\end{array}$ \\
\hline 5 & Occupation & $\begin{array}{l}\text { Total } \chi 2=60.8, d f=5, P<0.001 \text { high sig. } \\
\text { For Males }-\chi 2=53.2, d f=5, P<0.001 \text { high sig. } \\
\text { For Females }-\chi 2=9.2, d f=3, P<0.001 \text { high sig. }\end{array}$ \\
\hline 6 & Family history & $\begin{array}{l}\text { Total }-\chi 2=201.14, d f=1, p<0.001 \text {, high sig. } \\
\text { Male }-\chi 2=134.76, d f=1, p<0.001, \text { high sig. } \\
\text { Females- } \chi 2=57.92, d f=1, p<0.001, \text { high sig. }\end{array}$ \\
\hline 7 & Physical activity & $\begin{array}{c}\text { Total }-\chi 2=32.2, d f=2, P<0.001 \text { high sig For Males }-\chi 2=24.5, d f=2, p<0.001 \text {, high sig } \\
\text { For Females }-\chi 2=7.6, d f=2, p<0.05 \text {, sig }\end{array}$ \\
\hline 8 & Alcohol consumption & Total $-\chi 2=79.9, \mathrm{df}=1, \mathrm{P}<0.001$ high sig \\
\hline 9 & Tobacco use & Total $\chi 2=112.1, \mathrm{df}=3, \mathrm{P}<0.001$ high sig \\
\hline & & $\begin{array}{l}\text { For Males }-\chi 2=64.1, \mathrm{df}=3, \mathrm{p}<0.001, \text { high sig } \\
\text { For Females- } \chi 2=35.1, \mathrm{df}=3, \mathrm{p}<0.001, \text { high sig }\end{array}$ \\
\hline 10 & Obesity & $\begin{array}{l}\text { Total }-\chi 2=61.2, d f=1, P<0.001, \text { high sig } \\
\text { For Males }-\chi 2=62.06, d f=1, p<0.001, \text { high sig } \\
\text { For Females }-\chi 2=5.25, d f=1, p<0.05, \text { sig }\end{array}$ \\
\hline 11 & Mental Stress & $\begin{array}{l}\text { Total }-\chi 2=33.8, d f=2, P<0.001 \text { high sig } \\
\text { For Males }-\chi 2=40.0, d f=2, p<0.001 \text {, high sig } \\
\text { For Females- } \chi 2=3.31, d f=1, p>0.5 \text {, Not Sig }\end{array}$ \\
\hline 12 & Dietary pattern & $\begin{array}{l}\text { Total }-\chi 2=7.84, d f=1, p<0.01, \text { sig } \\
\text { For Males }-\chi 2=11.15, d f=1, p<0.001 \text {, high sig } \\
\text { For Females- } \chi 2=0.64, d f=1, p>0.5 \text {, Not Sig }\end{array}$ \\
\hline 13 & Religion & $\begin{aligned} \text { Total- } \chi 2 & =4.0, \mathrm{df}=2, \mathrm{P}>0.5, \text { Not Sig } \\
\text { Males }-\chi 2 & =4.20, \mathrm{df}=2, \mathrm{p}>0.5 ; \text { Not Sig } \\
\text { Females }-\chi 2 & =0.13, \mathrm{df}=2, \mathrm{p}>0.5 ; \text { Not Sig }\end{aligned}$ \\
\hline
\end{tabular}




\begin{tabular}{|c|c|c|c|c|c|}
\hline \multirow[t]{38}{*}{14} & \multicolumn{2}{|c|}{ Socioeconomic status } & \multicolumn{3}{|c|}{$\begin{array}{l}\text { Total } \chi 2=8.4, d f=4, p>0.5 \text { Not Sig } \\
\text { For Males }-\chi 2=11.9, d f=4, p<0.5 \text {, significant. } \\
\text { For Females }-\chi 2=7.14, d f=3, p>0.5 \text {, Not Sig }\end{array}$} \\
\hline & \multicolumn{5}{|c|}{ Table IV: Results of Multivariate analysis. ${ }^{*}$} \\
\hline & SR.No & VARIABLE & ODDS RATIO & $95 \% \mathrm{Cl}$ & P VALUE \\
\hline & \multirow[t]{3}{*}{1} & Gender & & & \\
\hline & & - Female & 1 (Reference) & & \\
\hline & & - Male & 2.07 & $1.47-2.92$ & Sig \\
\hline & \multirow[t]{3}{*}{2} & Marital Status & & & \\
\hline & & - Married & 1 (Reference) & & \\
\hline & & - Widow/er & 3.49 & $2.44-5.0$ & Sig \\
\hline & \multirow[t]{3}{*}{3} & Socioeconomic status & & & \\
\hline & & - Lower class & 1 (Reference) & & \\
\hline & & - Higher class & 1.26 & $0.95-1.68$ & Non Sig \\
\hline & \multirow[t]{3}{*}{4} & Family History & & & \\
\hline & & - Positive & 1 (Reference) & & \\
\hline & & - Negative & 7.26 & $5.39-9.77$ & Sig \\
\hline & \multirow[t]{4}{*}{5} & Physical activity & & & \\
\hline & & - Heavy & 1 (Reference) & & \\
\hline & & - Sedentary & 1.70 & $0.83-3.48$ & Non Sig \\
\hline & & - Moderate & 1.16 & $0.59-2.27$ & Non Sig \\
\hline & \multirow[t]{3}{*}{6} & Diet & & & \\
\hline & & - Vegetarian & 1 (Reference) & & \\
\hline & & - Non vegetarian & 1.60 & $1.16-2.21$ & Sig \\
\hline & \multirow[t]{5}{*}{7} & Alcohol & & & \\
\hline & & - Non alcoholic & 1 (Reference) & & \\
\hline & & - Mild & 2.02 & $0.94-4.35$ & Non Sig \\
\hline & & - Moderate & 2.69 & $1.24-5.80$ & Sig \\
\hline & & - Severe & 3.86 & $2.78-5.35$ & Sig \\
\hline & \multirow[t]{5}{*}{8} & Tobacco & & & \\
\hline & & - Non tobacco user & 1 (Reference) & & \\
\hline & & - Mild & 2.16 & $0.89-5.24$ & Non Sig \\
\hline & & - Moderate & 2.77 & $1.56-4.91$ & Sig \\
\hline & & - Severe & 5.13 & $3.52-7.47$ & Sig \\
\hline & \multirow[t]{3}{*}{9} & Obesity & & & \\
\hline & & $-<25 \mathrm{BMI}$ & 1 (Reference) & & \\
\hline & & $->25 \mathrm{BMI}$ & 3.14 & $2.36-4.17$ & Sig \\
\hline & \multirow[t]{3}{*}{10} & Mental Stress Score & & & \\
\hline & & - Score $<40$ & 1 (Reference) & & \\
\hline & & - Score $>40$ & 1.20 & $1.10-1.80$ & Sig \\
\hline
\end{tabular}

(* Values for all variables are age adjusted.)

This shows that, out of 14 variables studied, total 2 variables were found to have no significant association in occurrence of hypertension. These variables were Physical activity and socioeconomic status. (Table IV)

In these variables, Family history topped the list of statistical significant variables followed by consumption of

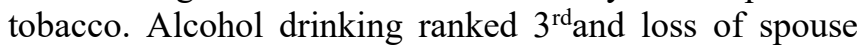
stood out to be $4^{\text {th }}$ variable. Obesity on the $5^{\text {th }}$ position showed the Odd's ratio $=3.14$ while male gender had also the $\mathrm{OR}=2.7$. The persons having the mixed dietary pattern also found to have statistical significant correlation with the $\mathrm{OR}=1.6$. Comparison of Univariate analysis based on chi square values and Multivariate analysis based on Odd's ratio indicated the matching and comparable results. From this, it could be said that, the variables influencing the occurrence of hypertension in the study group in the decreasing order of significance were - Family history, Tobacco use, Alcohol use, Marital status, Obesity, Male Gender, Dietary pattern and Mental stress.

\section{DISCUSSION}

A field based descriptive cross sectional study was carried out in the age group of above 40 years in a rural township. A total of 3600 participants were surveyed to know the prominent risk factors associated with hypertension. In the present study, prevalence of hypertension was found to be $5.92 \%$ which was comparable with other prevalence studies in rural areas. ${ }^{1,4,7}$ Few studies ${ }^{8,9}$ reported much 
higher prevalence as compared to present study. This could be due to differences at nutritional habits, age accumulation effects and social and cultural diversities. Gender difference in prevalence was observed in present study, which showed higher Hypertension prevalence among Males. This finding was in line with studies done earlier at national level ${ }^{8}$. This could be ascribed to, nutritional factors and lifestyle risk factors like smoking, tobacco chewing and alcohol consumption apart from psychosocial stress. The rise in the number of cases with increasing age was found to be statistically significant $(\mathrm{P}<0.001)$. Previous few studies reported similar increasing prevalence with age $e^{4,9,10,11}$. It is speculated that due to ageing process and cumulative socio-culturalenvironmental factors that lead to rise in prevalence with age. Whereas, Religion wise and socioeconomic status wise difference was not statistically significant in the present study. Possible reasons could be that, in higher SES stratum, the sedentary work, obesity and stress perception could be attributable while as, in Lower SES stratum, higher daily living stress, substance abuse might be the factors operating. The study findings could be comparable with few studies 10,11,12. Prevalence of Hypertension was seen more in Widow/widower group (18.64\%) than Married group. (4.8\%) Similarly, Illiterate group showed $8.9 \%$ HTN prevalence as compared to $4.32 \%$ in Literate group. Such findings are in unison with few previous studies. ${ }^{4,10,13}$ When comparison were made between people with 'No Job' and rest of the people 'doing one or the other job', the prevalence was seen more in later group. Various comparative accounts of other studies showed similar results. ${ }^{10,11,13}$ In Present study, Multivariate analysis showed significant difference amongst participants having positive family history of Hypertension $(19.76 \%)$ compared to rest of the participants. Comparable results were given by few other studies ${ }^{10,14,15}$ which points out towards strong genetic component as well as possible role of dietary habits which do run in the families. Study participants involved in sedentary type of Physical activity were found to be having higher prevalence of hypertension on univariate analysis, but on Multivariate analysis, it was not statistically significant. (OR- $1.76,95 \%$ CI $0.83-3.48$ ) Contrary to this, many study reported higher prevalence among sedentary wok pattern. ${ }^{16,17}$ Significant association was seen in dietary pattern and hypertension in present study. Among participants having mixed dietary pattern had $6.68 \%$ prevalence compared to $4.35 \%$ among Vegetarian diet participants. (OR - 1.6 CI -1.16-2.21) Many studies reported similar findings ${ }^{14,18}$ which could be due to some components of animal products, high calorie / fat intake responsible. Non-alcoholic group showed less prevalence of hypertension as compared to alcoholic group. $(\chi 2=79.9, \mathrm{df}=1, \mathrm{P}<0.001)$ And, subjects using any form of tobacco had higher prevalence of hypertension compared to their counterpart. $(\chi 2=112.1, \mathrm{df}=3, \mathrm{P}<0.001)$. Shikha Singh et al. ${ }^{8}$ (2017) and few other studies ${ }^{18,19}$ also reported similar results where tobacco use known to be important risk factor for higher hypertension prevalence. Obesity and prevalence of hypertension was seen statistical significant. BMI $>25$ had $11.4 \%$ prevalence while three times less prevalence in non-obese was seen in present study. Rastogi T. et al. (2004) ${ }^{20}$ reported similar findings. BMI is an indicator of obesity which is a direct hypothesized risk factor for hypertension. Multivariate analysis showed significant association between mental stress and hypertension prevalence. (OR - 1.2 CI -1.101.80). Gupta R. et al. ${ }^{21}$ reported findings in unison with present study. Whereas some studies ${ }^{22}$ found no relation in between them.

\section{CONCLUSIONS}

A field based descriptive cross-sectional study on hypertension with appreciation of both possible modifiable and non-modifiable risk factors was carried out in rural township of Western Maharashtra. From present study it can be concluded that, prevalence of hypertension is on the rise in rural area as well. Advancing age is one of the most important variables related to hypertension. The risk of hypertension increases with positive family history and in male gender. Use of tobacco in one or the other form, alcohol consumption and resorting to non-vegetarian diet are the other contributory factors and the risk is more in the widowed persons as well as in those who are obese. Screening programmes with continuing health education at rural areas for timely diagnosis and further treatment are to be stressed at policy formation. Recommendations for promoting increased physical activity and inclusion of vegetables in the diet while restricting alcohol and tobacco use with control of body weight is desired. Cross sectional nature of the study, limited age group and only rural area study are some of the limitations of the study.

Acknowledgements: The authors would like to thank all the participants and RHTC Tasgaon staff members for participating in the study.

\section{REFERENCES}

1. Arvind Kumar, SandeepGarg, Hemlata Gupta. A Study of Prevalence of Risk Factors for Coronary Artery Diseases in Asymptomatic Middle Aged and Elderly Subjects. JK science. 2005; 7 (2): 61-63

2. Gaziano TA. Cardiovascular disease in the developing world and its cost-effective management. Circulation 2005; 112:3547-3553.

3. Kulkarni AP, Baride JP. Textbook of Community Medicine, Kaushik K Gada, Vora Medical Publishers, Mumbai, $1^{\text {st }}$ edition, 1998: 418-419. 
4. Deb S, Dasgupta A. A study on risk factors of cardiovascular diseases in an urban health center of Kolkata. Indian J Community Med 2008;33:271-5

5. Arun K Sharma, ShilpaBhardwaj, Sanjay Chaturvedi. Predictors of Hypertension in an Urban Indian Population. Indian Heart Journal 2006;58:21-27

6. Gurmeet Singh et al. 'Presumptive Stressful Life Events Scale. (PSLES)- A NewStressful Life Events Scale for Use in India.' Indian Journal of Psychiatry 1984;26 (2): 107-114

7. Goyal A and Yusuf S. 'The Burden Of Cardiovascular Disease In The Indian Subcontinent.' Ind. J. Med. Res 2006; 124: 235-244

8. Singh S, Shankar R, Singh GP. Prevalence and Associated Risk Factors of Hypertension: A Cross-Sectional Study in Urban Varanasi. Int J Hypertens. 2017;2017:5491838.

9. Galav, Bhatanagar R, Meghwal S. et al. Prevalence of hypertension among rural and urban population in Southern Rajasthan. Indian Journal of Community Medicine.2015:6(2):41-45.

10. Ingale AS, Dixit JV. Prevalence of hypertension, awareness and health seeking behaviour among adults residing in field practice area of urban health training centre, government medical college Aurangabad. National Journal of Community Medicine.2017;8(1):31-36

11. Ahmed, Rahman M., Hasan R. et al. Hypertension and associated risk factors in some selected rural areas of Bangladesh. International Journal of Research in Medical Sciences. 2014: 2(3):925

12. S. Padmavati. Prevention of Heart Disease in India in The $21^{\text {st }}$ Century: Need for a Concerned Effort. Indian Heart Journal 2002; 54:99-102.

13. Rajeev Gupta, Kaul V, et al. Trends in Prevalence of Coronary Risk Factors in An Urban Indian Population:
Jaipur Heart Watch-4. Indian Heart Journal 2007; 59(4):346-353

14. Arun K Sharma, ShilpaBhardwaj, Sanjay Chaturvedi. Predictors of Hypertension in an Urban Indian Population. Indian Heart Journal 2006;58:21-27

15. Gopinath N, Chaddha SL, Shekhawat S, Tandon R. A 5Year Follow Up Study of Hypertension in a Rural Community. Indian Heart Journal 1995; 47:129-133.

16. Swamy HM et al. 'Population Based Study of Hypertension among the Elderly in Northern India'. Indian Journal Of Public Health.2002;116(1): 45-49

17. Malhotra $P$ et al. 'Prevalence and Determinants of Hypertension In An Unindustrialized Rural Population Of North India' South Asian Journal Of Preventive Cardiology, 2000; 4:5-12

18. Dhungana RR, Pandey AR, Bista B, Joshi S, Devkota S. Prevalence and Associated Factors of Hypertension: A Community-Based Cross-Sectional Study in Municipalities of Kathmandu, Nepal. Int J Hypertens. 2016;2016:1656938.

19. Marianne AB, Van der Sande, et al. Family History: An opportunity for Early Inventions and Improved Control of Hypertension, Obesity, and Diabetes' Bulletin of World Health Organizatio,2001; 79:321-328.

20. Rastogi T, Vaz M, Spiegeman D, Reddy KS, et al. 'Physical Activity and Risk of Coronary heart disease in India. Int. J. Epidemiol. 2004; 33:759-767.

21. R Gupta, V P Gupta, N S Ahluwalia. Educational status, coronary heart disease, and coronary risk factor prevalence in a rural population of India. BMJ 1994;309:1332-1336

22. Gupta $\mathrm{R}$ et al. Correlation of Smoking, Blood Pressure Levels and Hypertension Prevalence in Urban and Rural Subjects. JAPI 1997; 45(12):919-922

\section{Source of Support: None Declared Conflict of Interest: None Declared}

